\title{
EFFECTS OF SEPARATION METHODS ON YIELD AND QUALITY OF BIOCRUDE AFTER THERMOCHEMICAL LIQUEFACTION OF A MARINE MICROALGAE
}

\author{
B. E. Eboibi* \\ Department of Chemical Engineering, Delta State University, Oleh Campus, Delta State, NiGERia \\ E-mail addresses: blessingeboibi@gmail.com
}

\begin{abstract}
Hydrothermal liquefaction (HTL) is a promising process for conversion of microalgae to biocrude that is upgradable to liquid transportation fuel. However, there is yet to be established standard separation method for product recovery. In this paper, the effects of separation methods on yields and quality of biocrude were investigated. HTL studies were conducted at operating conditions of $350^{\circ} \mathrm{C}$ and $5 \mathrm{~min}$ with solids loading of $16 \mathrm{wt} \%$. The results shows that multistep extraction of product mixture led to $\sim 65 \mathrm{wt} \%$ biocrude yield compared to $\sim 48 \mathrm{wt} \%$ for single step. Multistep extraction led to increase in biocrude yield, with lower yields in solid residue and aqueous phases. However with the trade-offs of nitrogenous and oxygenated compounds in biocrude. Quality of biocrude was improved after vacuum evaporation of biocrude phase at $100{ }^{\circ} \mathrm{C}$ when compared to evaporation at $40^{\circ} \mathrm{C}$. The separation methods had little impact on biocrude energy density, which varies between $34 \mathrm{MJ} / \mathrm{kg}$ and $38 \mathrm{MJ} / \mathrm{kg}, 1.5$ and 1.7 for hydrogen-tocarbon atomic ratios.
\end{abstract}

Keywords: Biocrude; Energy; Hydrothermal liquefaction; Microalgae; Separation methods

\section{INTRODUCTION}

Hydrothermal liquefaction (HTL) is a promising process for processing wet microalgae biomass under subcritical water conditions to produce hydrocarbon, usually referred to as biocrude $[1,2]$. HTL is important in sustainable production of energy and chemicals, and it is a green process. Importantly, HTL obviates high energy-intensive step associated with drying of biomass as normally applied in other thermochemical processes such as gasification and pyrolysis $[3,4]$.

Products obtained from HTL of microalgae are biocrude, solid residue, aqueous and gas phases $[5,6]$. Typically, HTL of algae biomass first produces liquid product mixture, and it is from it that the HTL products are obtained after series of extraction protocols using organic solvent. The product mixture comprises biocrude (mostly hydrocarbons), aqueous phase (wastewater) and residues. Normally, during work-up of separation protocols for product recovery, organic solvent is added to the product mixture, which dissolves and allow phase separation for fractional yields.

A review of the literature revealed that there is yet to be an established standard separation procedure to obtain products after HTL of algae. In addition, dichloromethane (DCM) is the mostly used organic solvent $[7,8]$ to extract hydrocarbons from HTL product mixture.

Moreover, the residue and aqueous phases contains some hydrocarbons. Hence, it is assumed that further processing of residue and aqueous fractions (extracting biocrude) could influence product yields. However, there are limited studies on this aspect of additional extraction of biocrude from solid and aqueous phases. The essence of such studies would provide data on yield and properties of products for different separation methods. Although Valdez and Savage [9] investigated treatment of residues and aqueous phase, product properties were not reported. Xu and Savage, [10] reported yields from treating HTL-aqueous phase for kinetic parameters. Other studies have been mostly on recycling of aqueous phase to algae growth ponds, to cultivate algae biomass $[11,12,13]$. These reports have demonstrated feasibility of recovering additional yields from effluents and residues, however more research investigations on product recovery is necessary.

Furthermore, prior to obtaining biocrude from biocrude phase (mixture of biocrude and solvent), the phase is subjected to vacuum evaporation, in order to 
remove used solvent. In almost HTL experiments, DCM is evaporated at $40^{\circ} \mathrm{C}$, the remnant solution defined as biocrude. It is possible that certain amount of water would remain in the biocrude. Since dichloromethane to an extent is soluble in water [14], its solubility may impact products separation. Also, it could influence transfer of molecules between phases, such as from solid and aqueous phases into the primary product, biocrude.

As a result almost reported literature data on biocrude, particularly on yield may be a concern. Biocrude obtained from HTL, likewise pyrolysis of algae had water content $[1,15]$. Shakya et al., [5] reported that biocrude contains about $4 \%$ to $9 \%$ water content, which is estimated alongside its yield. Occurrence of water molecules in biocrude are in the form of oxygenated compounds such as aldehydes, carboxylic acids, esters, and ketones. Presence of $\mathrm{O}$ - and $\mathrm{N}$ compounds are undesired in biocrude, as it significantly reduces its 'quality' [2]. Therefore, removal/reduction of oxygenated compounds in biocrude is necessary in order to improve its fuel properties.

Moreover, the yield in biocrude is one of the important factors to estimate parameters such as energy recovery, energy conversion ratio (ECR), technoeconomic analysis and life cycle assessment, and energy return on investment (ERoI) on viability of HTL-microalgae-liquid fuels. Thus, separation method(s) that could give a near zero-error on the yield of biocrude is necessary. Therefore, the aim of this reported study is to elucidate the effects of separation methods on yield and quality of biocrude.

\section{MATERIALS AND METHODS}

\subsection{Materials}

A marine microalga Tetraselmis sp. was used in the present study. The microalga cultivation, harvesting and preserving prior to HTL experiments have been reported elsewhere [[16, 17]. HTL experiment was conducted at the Pilot plant, Biotechnology Division, Aban Infrastructure Pvt Ltd., India. A reagent grade organic solvent dichloromethane (DCM with over 99\% purity) obtained from Sigma-Aldrich was used in this study.

\subsection{Methods: Hydrothermal liquefaction}

Hydrothermal liquefaction of the alga biomass were conducted batch-wise using a custom built highpressure $1 \mathrm{~L}$ Inconel reactor with an inbuilt magnetic stirrer. Based on previous studies, the HTL experimental studies were conducted at fixed reaction temperature of $350^{\circ} \mathrm{C}, 5 \mathrm{~min}$ reaction time with alga solids loading of $16 \mathrm{w} / \mathrm{w} \%$. Typically, for each HTL run, $60 \mathrm{~g}$ of Tetraselmis sp. alga biomass mixed with $300 \mathrm{~mL}$ of deionised water was loaded into the reactor. Then the reactor was sealed and heated to $350^{\circ} \mathrm{C}$ using an inbuilt electrical heating jacket with an approximate heating rate of $\sim 20^{\circ} \mathrm{C} / \mathrm{min}$ and maintained at $\pm 4{ }^{\circ} \mathrm{C}$ for 5 min reaction time. After completion of the reaction time, the reactor was cooled to room temperature, followed by venting off the gas via the gas valves. Then the product mixtures were transferred to a separating funnel followed by using different separation protocols to obtain fractional yields.

\subsection{HTL Product Separation Protocols}

This section describes the different separation protocols to achieve fractional yields.

\subsubsection{Method $1\left(M_{1}\right)$}

This is the conventional method usually employed to estimate HTL product yields after complete reaction. In this method, after releasing the gas products as mentioned previously, the product mixture were transferred to a separating funnel. The reactor wall and parts were rinse with solution containing $50 \mathrm{~mL}$ (each of DCM and water) three times, and the rinse solution added to the separating funnel. Then equal amount of DCM to product mixture (about $360 \mathrm{~mL}$ of DCM) were added to the separating funnel containing the product mixture, followed by manual agitation for $2 \mathrm{~min}$ in order to enhance extraction. Then the separating funnel was allowed to stand for $12 \mathrm{hrs}$, for phase separation. After $12 \mathrm{hrs}$ the product mixture separates into three layers; an upper layer brownish in colour, referred as aqueous phase (also known as wastewater), a middle layer dark in colour referred as biocrude phase (a mixture of biocrude and DCM), and a bottom layer the residue.

These layers were collected by filtration using Whatman filter papers $(47 \mathrm{~mm}$, pore size $=0.45 \mathrm{~mm})$. First, the bottom layer was collected and dried at $\sim 100^{\circ} \mathrm{C}$, to remove DCM and water, weighed and defined as solid residue [18]. Followed by the middle layer (biocrude phase), where it was vacuum evaporated at $\sim 40^{\circ} \mathrm{C}$ to remove $\mathrm{DCM}$, the remnant defined as biocrude [19]. Finally the aqueous phase (AQ) was collected, dried at $\sim 100^{\circ} \mathrm{C}$ to remove water and DCM, weighed, and referred as dissolved aqueous solids (DAS) [20]. The schematic view of HTL production and separation procedure for method $1\left(M_{1}\right)$ is presented in Fig. $1 M_{1}$ 


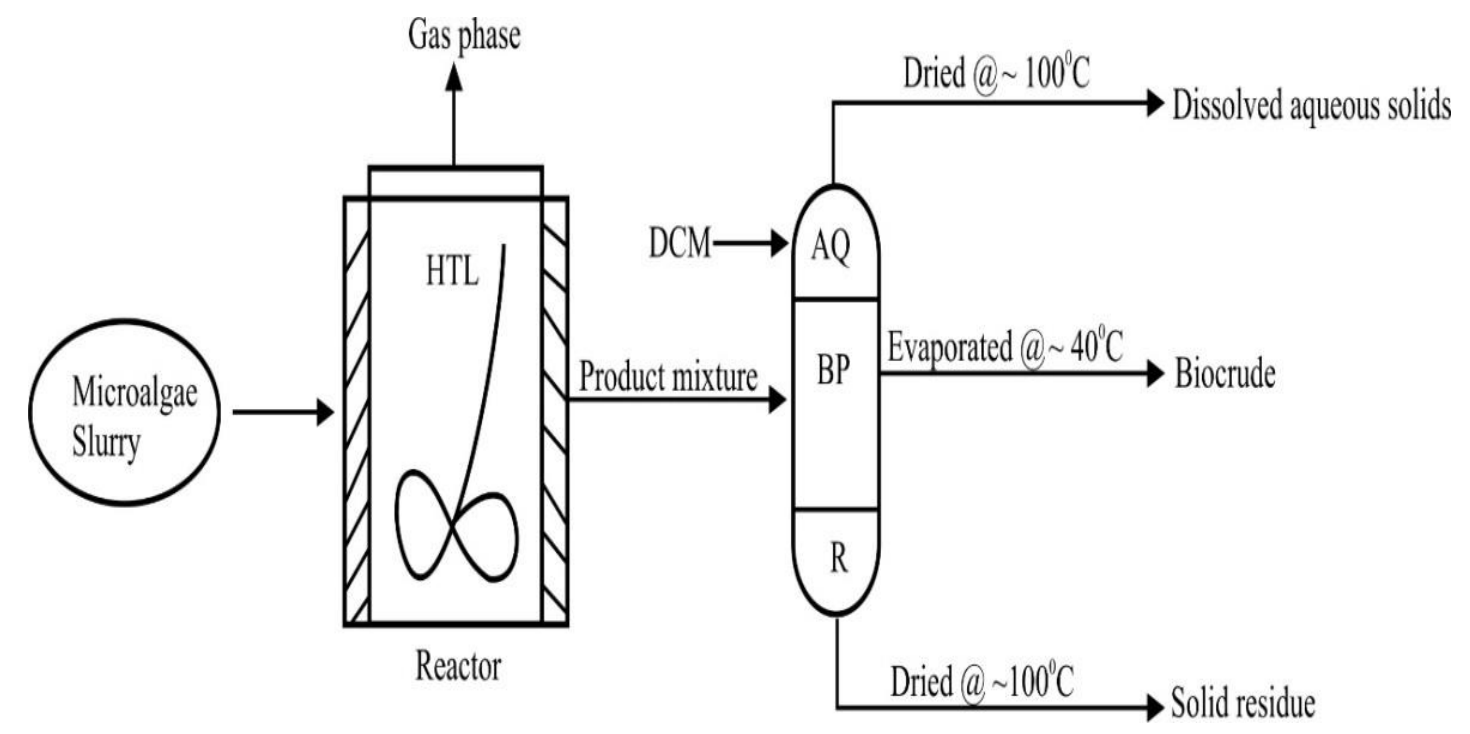

Figure. 1M: HTL of microalgae production and separation procedure for $M_{1}$

HTL: hydrothermal liquefaction. DCM: dichloromethane. AQ: aqueous phase. BP: biocrude phase. R: residue. @: at.

\subsection{2 $\operatorname{Method} 2\left(M_{2}\right)$}

This method is similar to $\mathrm{M}_{1}$, except the DCM was vacuum evaporated at $\sim 100^{\circ} \mathrm{C}$. Other product fractions solid residue, dissolved aqueous solids and gas phases were obtained as explained in $\mathrm{M}_{1}$. The schematic view of the production and separation procedure for $\mathrm{M}_{2}$ is shown in Fig. $1 \mathrm{M}_{2}$.

\subsubsection{Method $3\left(M_{3}\right)$}

$\mathrm{M}_{3}$ also follows similar separation steps as described in $\mathrm{M}_{1}$, except that additional DCM was added to the aqueous phase, in order to extract additional hydrocarbons. After addition of DCM, it was agitated for about $2 \mathrm{mins}$, and allowed to stand for $6 \mathrm{hr}$. After $6 \mathrm{hr}$, two layers were formed, a bottom layer (biocrude phase + DCM) and an upper layer (aqueous phase, amber colour). Again the biocrude phase was vacuum evaporated at $100^{\circ} \mathrm{C}$. Similarly, the upper layer, (aqueous phase) and residue were quantified as explained in $\mathrm{M}_{1}$. The schematic view of the production and separation procedure for $\mathrm{M}_{3}$ is shown in Fig. $1 \mathrm{M}_{3}$.

\subsubsection{Method $4\left(M_{4}\right)$}

Method $\mathrm{M}_{4}$ follows similar procedure as explained in $M_{1}$. The only difference with $M_{4}$ is that the residue fraction went through another solvent extraction step. Here equal amount of DCM to the residue were added to the residue in a separating funnel. Then agitated and allow to stand for $6 \mathrm{hr}$.

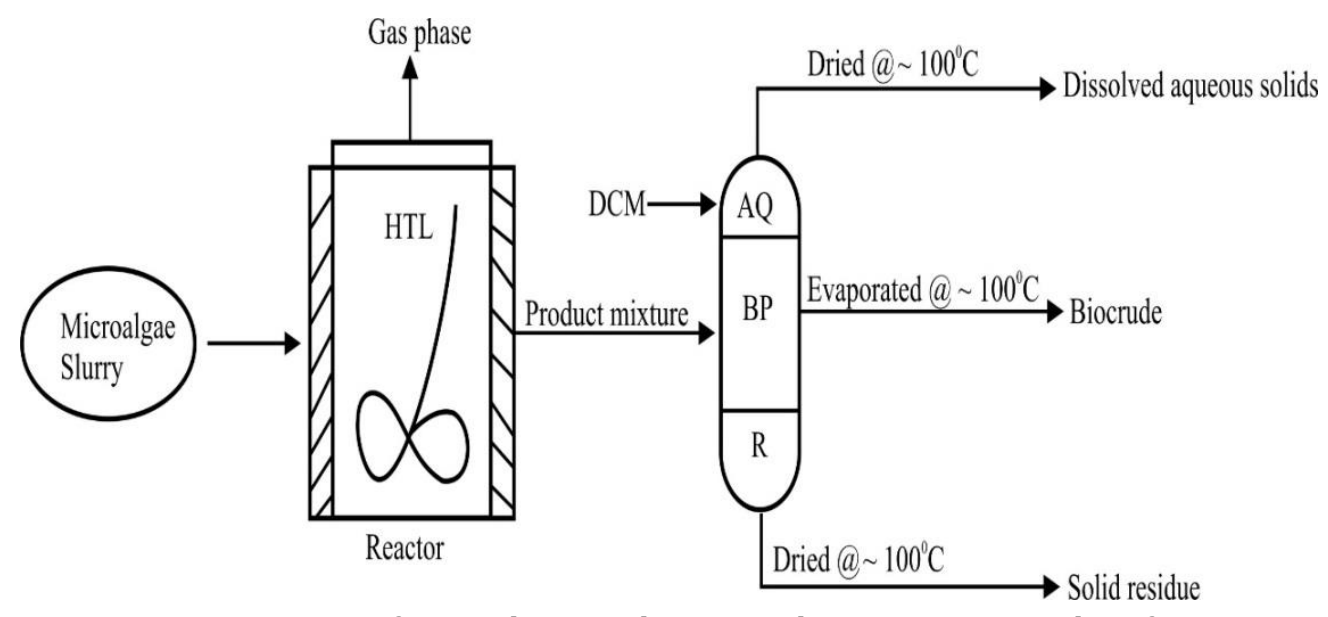

Figure $1 M_{2}$ : HTL of microalgae production and separation procedure for $\mathrm{M}_{2}$

HTL: hydrothermal liquefaction. DCM: dichloromethane. AQ: aqueous phase. BP: biocrude phase. R: residue. @: at. 


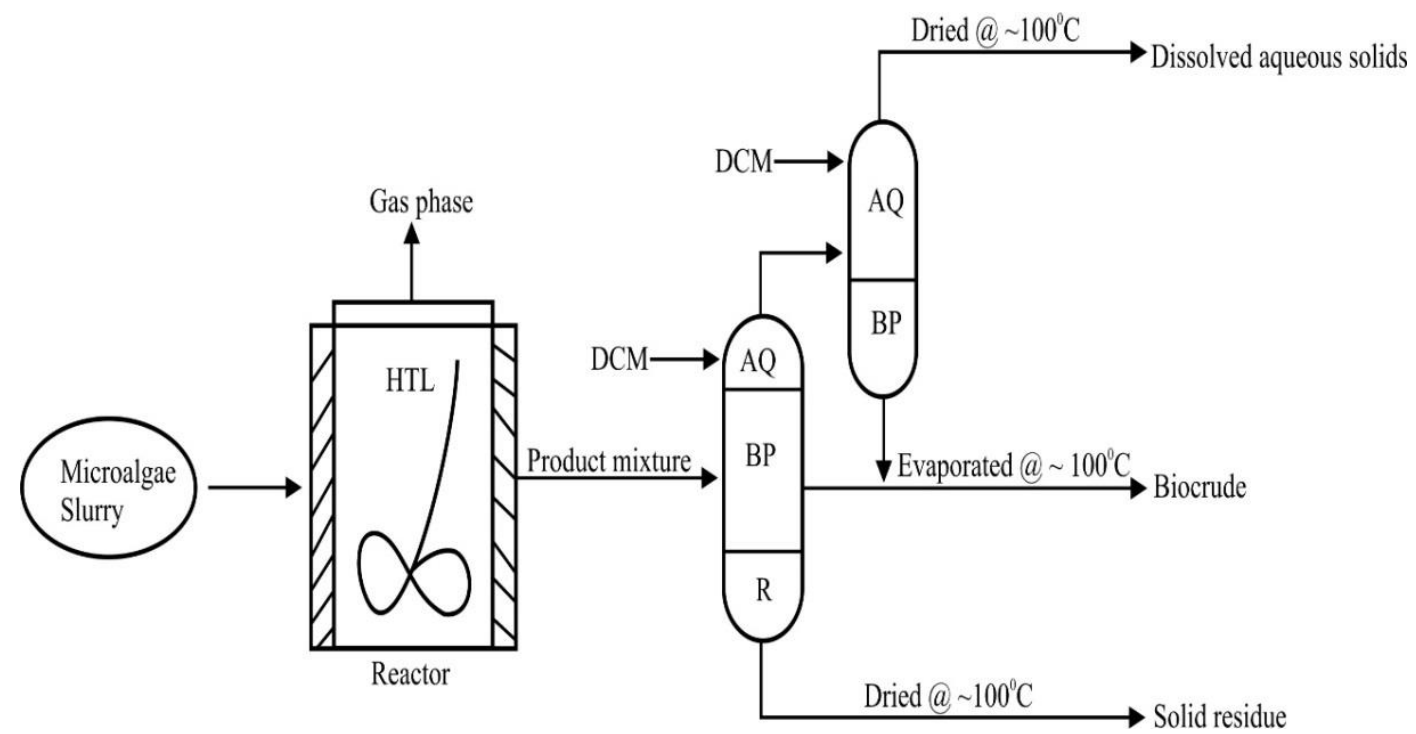

Figure 1M3: HTL of microalgae production and separation procedure for $M_{3}$

HTL: hydrothermal liquefaction. DCM: dichloromethane. AQ: aqueous phase. BP: biocrude phase. R: residue. @: at.

Thereafter two layers were obtained, an upper layer (biocrude phase) and a bottom layer (residue). The residue was decanted, dried at $\sim 100^{\circ} \mathrm{C}$ and weighed. This dried fraction was defined as solid residue. Then DCM was vacuum evaporated from the biocrude phase at $100^{\circ} \mathrm{C}$. The remaining fraction was weighed and defined as biocrude. The gas and aqueous phases were quantified as described previously in $\mathrm{M}_{1}$. The schematic view of the production and separation procedure for $\mathrm{M}_{4}$ is shown in Fig. $1 \mathrm{M}_{4}$.

\subsubsection{Method $5\left(M_{5}\right)$}

$\mathrm{M}_{5}$ is a multistep extraction protocol. This methods has similar procedure as $\mathrm{M}_{1}$ but both the residue and aqueous phase fractions simultaneously went through another solvent extraction step (as explained in method $M_{4}$ and $M_{3}$ ). In fact, $M_{5}$ is a combination of $M_{3}$ and $\mathrm{M}_{4}$. The schematic view of production and separation procedure for $\mathrm{M}_{5}$ is shown in Fig. $1 \mathrm{M}_{5}$.

\subsection{Product Yields and Analysis}

The yields in biocrude, solid residue, aqueous and gas phases were estimated in accordance to methods explained previously [21-23]. Briefly, the gravimetric yields in biocrude, solid residue and dissolved aqueous solids were determined by relating mass of biocrude, solid residue or dissolved aqueous solids to mass of algae loaded in the reactor.

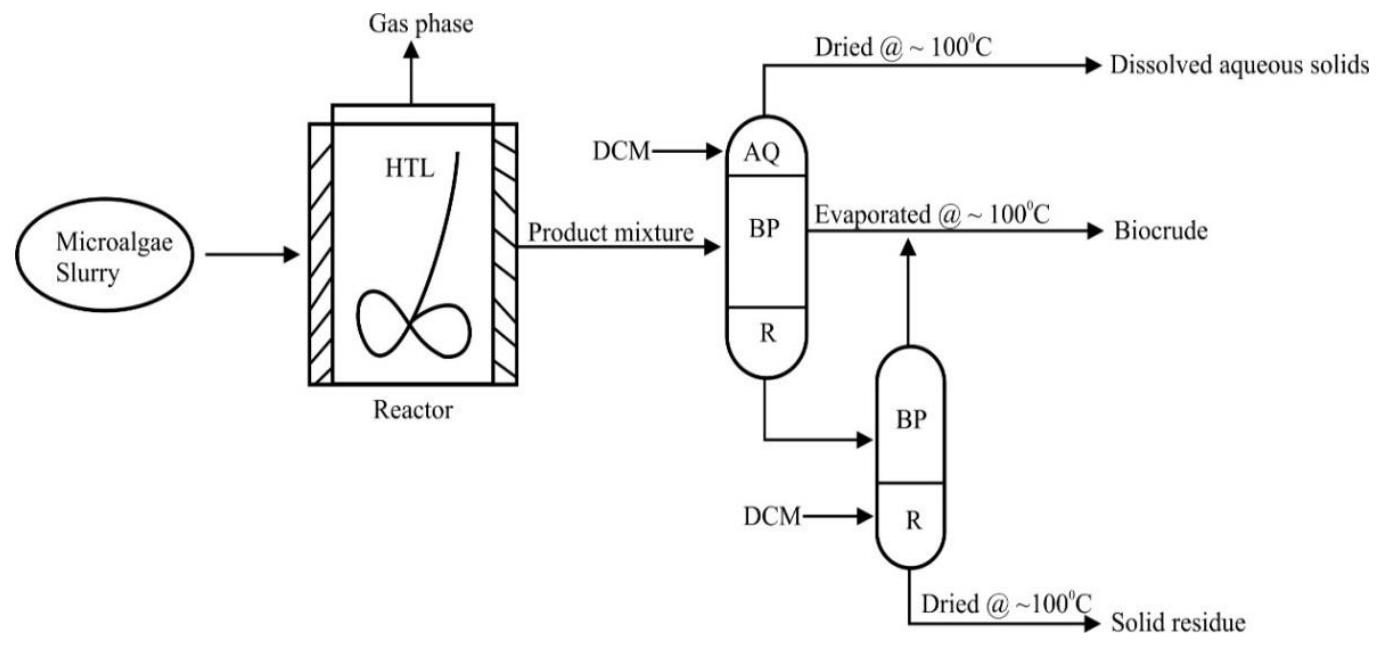

Figure. 1M4:HTL of microalgae production and separation procedure for $M_{4}$

HTL: hydrothermal liquefaction. DCM: dichloromethane. AQ: aqueous phase. BP: biocrude phase. R: residue. @: at. 


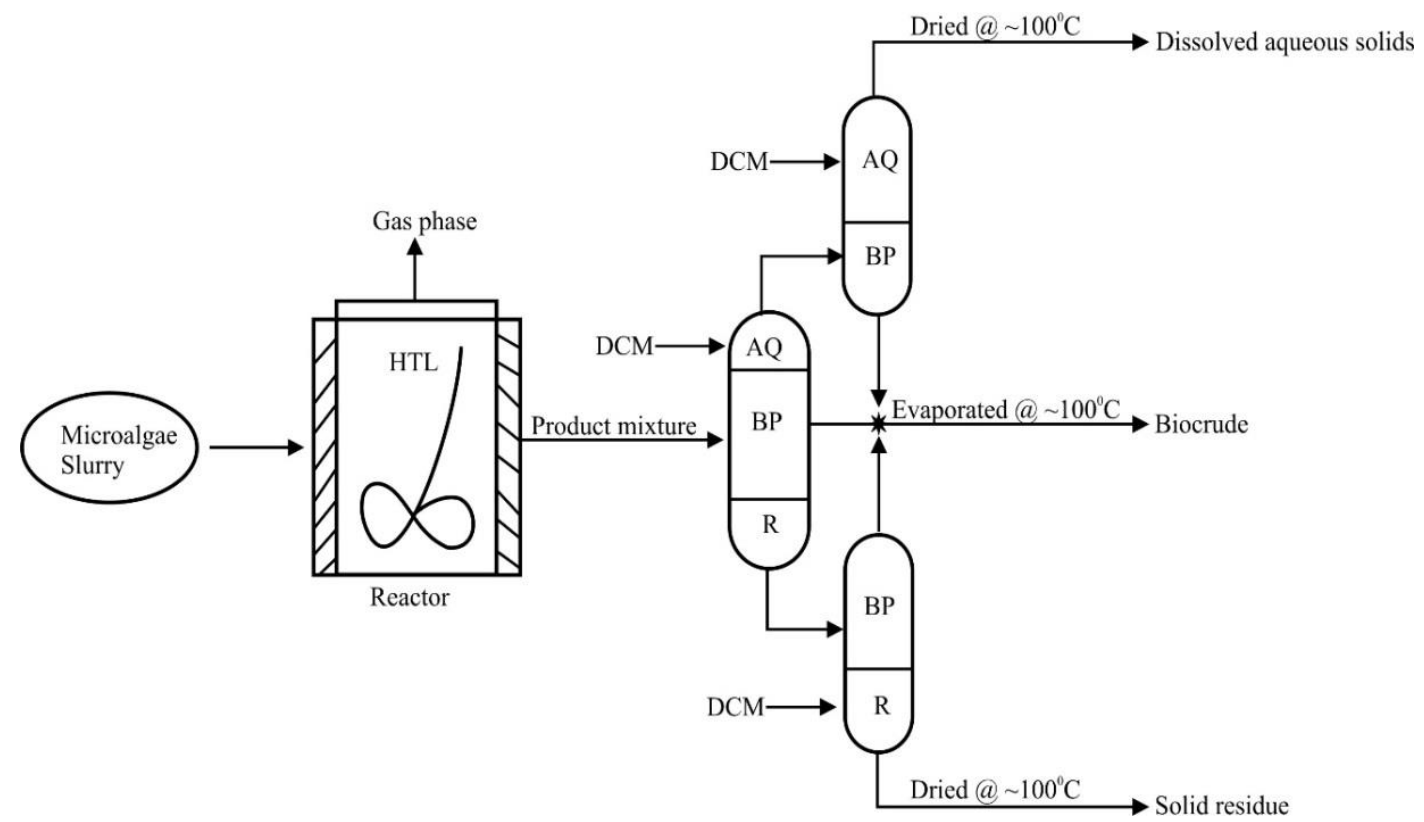

Figure. 1M: HTL of microalgae production and separation procedure for $M_{5}$

HTL: hydrothermal liquefaction. DCM: dichloromethane. AQ: aqueous phase. BP: biocrude phase. R: residue. @: at.

This is as shown in Eq. (1).

$$
\text { Yield }(\%)=\frac{\text { Mass of products }}{\text { Mass of algae loaded }} \times 100 \%
$$

Gas phase yields were obtained by difference (gas phase $=$ (biocrude + solid residue + dissolved aqueous solids)).

The higher heating value (HHV), chemical energy recovered in biocrude, and the hydrogen-to-carbon ratio were determined in accordance to methods explained previously $[20,24]$.

Sample of biocrudes (diluted to $2.5 \mathrm{v} / \mathrm{v} \%$ with acetone) were analysed with Gas Chromatography-Mass Spectrometer (GC-MS) (Agilent Technologies $6890 \mathrm{~N}$, equipped with Agilent HP-5 capillary column of $50 \mathrm{~m} \times 200 \mu \mathrm{m} \times 0.33 \mu \mathrm{m}$ ) in accordance to the method reported previously $[5,16]$.

\section{RESULTS AND DISCUSSION}

\subsection{Effect of Separation Protocols on HTL Product Yields}

The product yields (biocrude, solid residue, dissolved aqueous solids and gas phase) obtained from different separation methods are presented in Fig. 2. As shown in Fig. 2, there were substantial variations in yields, confirming effects of different separation procedures. The yields from $\mathrm{M}_{1}$ were $48 \mathrm{wt} \%$ biocrude yield, $23 \mathrm{wt} \%$ solid residue, $15 \mathrm{wt} \%$ dissolved aqueous solids and $14 \mathrm{wt} \%$ gas phase. The biocrude yield reduced from $48 \mathrm{w} \%$ (at $\mathrm{M}_{1}$ ) to $42 \mathrm{wt} \%$ (at $\mathrm{M}_{2}$ ). The decrease in biocrude suggest loss of light hydrocarbons and water molecules when the biocrude phase was evaporated at $100^{\circ} \mathrm{C}$. Which is one the reasons behind this modification as it is believed that some amounts of water molecules could still be part of biocrude phase [18]. To the best of my knowledge, this is the first report on comparison of HTL-biocrude after vacuum evaporation of biocrude phase at $40^{\circ} \mathrm{C}$ and $100^{\circ} \mathrm{C}$.

Although the boiling point of DCM is $\sim 40^{\circ} \mathrm{C}$, evaporating DCM from biocrude phase led to loss of light hydrocarbons, and more amounts could have been lost at $100^{\circ} \mathrm{C}$. However, the advantage of evaporating at $100^{\circ} \mathrm{C}$ is removal/reduction of water molecules, improving the quality of biocrude, which will be discussed later. In addition, there were no substantial differences in solid residue and dissolved aqueous solids derived from $\mathrm{M}_{2}$ compared to those derived from $\mathrm{M}_{1}$. About $23 \mathrm{wt} \%$ solid residue was obtained from $\mathrm{M}_{2}$ similar to $24 \mathrm{wt} \%$ for $\mathrm{M}_{1}$, while $15 \mathrm{wt} \%$ dissolved aqueous solids was achieved from $\mathrm{M}_{2}$.

For method $3\left(\mathrm{M}_{3}\right)$, there was an increase in biocrude yield and decrease in dissolved aqueous solids, as shown in Fig. 2. Recall that in $\mathrm{M}_{3}$ the aqueous phase went through another extraction step to obtain additional biocrude yield prior to quantification. The additional extraction step led to substantial increase in total biocrude yield from $42 \mathrm{wt} \%$ (at $\mathrm{M}_{1}$ ) to $49 \mathrm{wt} \%$, and reduction in dissolved aqueous solids from $15 \mathrm{wt} \%$ at $\mathrm{M}_{1}$ to $12 \mathrm{wt} \%$ at $\mathrm{M}_{2}$. In fact, about $7 \mathrm{wt} \%$ biocrude was obtained from further extraction of the aqueous phase, an amount which may need consideration in terms cost of solvent and time. The $7 \mathrm{wt} \%$ biocrude yield from multiple step extraction of aqueous phase was found to be within the range of $6.4 \%$ to $3.6 \%$ biocrude yield obtained by $\mathrm{Xu}$ and Savage [14] when reaction time 
was increased from $10 \mathrm{~min}$ to $60 \mathrm{~min}$ operating at a temperature of $350^{\circ} \mathrm{C}$.

It was found that extracting biocrude from aqueous phase were challenging due to solubility of solvent and water. Although more biocrude yield were derived from $\mathrm{M}_{3}$, it was similar to $48 \mathrm{wt} \%$ biocrude yield derived at $M_{1}$. This finding suggests that yields higher than $49 w t \%$ could be obtained if the biocrude phase were evaporated at $40^{\circ} \mathrm{C}$. The increase in yields of biocrude after solvent extraction of the aqueous phase confirms presence of organics in the aqueous phase. Therefore further extraction of aqueous phase leads to an increase in biocrude yield. Similar yield was obtained for solid residue compared to that from $\mathrm{M}_{2}$ and $\mathrm{M}_{1}$, however the dissolved aqueous solids reduced from $15 w t \%$ (at $\mathrm{M}_{2}$ ) to $11 \mathrm{wt} \%$ (at $\mathrm{M}_{2}$ ). Of course, the gas phase yield reduced, but since it was estimated by difference, it was still within the range of $7 \mathrm{wt} \%$ to $24 \mathrm{wt} \%$ of previous reports $[21,23,24]$.

For method $4\left(\mathrm{M}_{4}\right) 60 \mathrm{wt} \%$ biocrude yield was obtained, suggesting presence of unrecovered hydrocarbons. The hydrocarbons could have been fractionated along the residue as described in $\mathrm{M}_{1}$, or as a result of inefficient solvent extraction and more hydrocarbons sticking to the porous solid matter. This leads to reduction in desired biocrude yield, while increasing yields in solid residue. Based on the data presented in Fig. 2, there were decrease in solid residue from $23 \mathrm{wt} \%$ (at $\mathrm{M}_{1}$ ) to $16 \mathrm{wt} \%$ (at $\mathrm{M}_{4}$ ), which confirmed organic recovery into biocrude following reprocessing of residue fraction.

Approximately $12 \mathrm{wt} \%$ biocrude yield was obtained from solvent extraction of residue, which lead to an increase in total biocrude yield. As expected the aquoeus phase remain unchanged, whereas the gas phase reduced from $14 w t \%$ (at $M_{1}$ ) to $10 w t \%$ (at $M_{4}$ ).

For method $\mathrm{M}_{5}, 66 \mathrm{wt} \%$ biocrude yield was achieved. When compared with $\mathrm{M}_{1}$, the SR and DAS reduced from $23 w t \%$ and $15 w t \%$ to $13 w t \%$ and $11 w t \%$, respectively. This study has shown that multistep extraction improves biocrude yield compared to sinlge-step extraction. This suggests that multistep extraction has substantial effects on HTL yields, but at the expense of more organic solvent. Moreover, knowing the effects of the modified separation methods on quality of products is important, which will be discuss later.

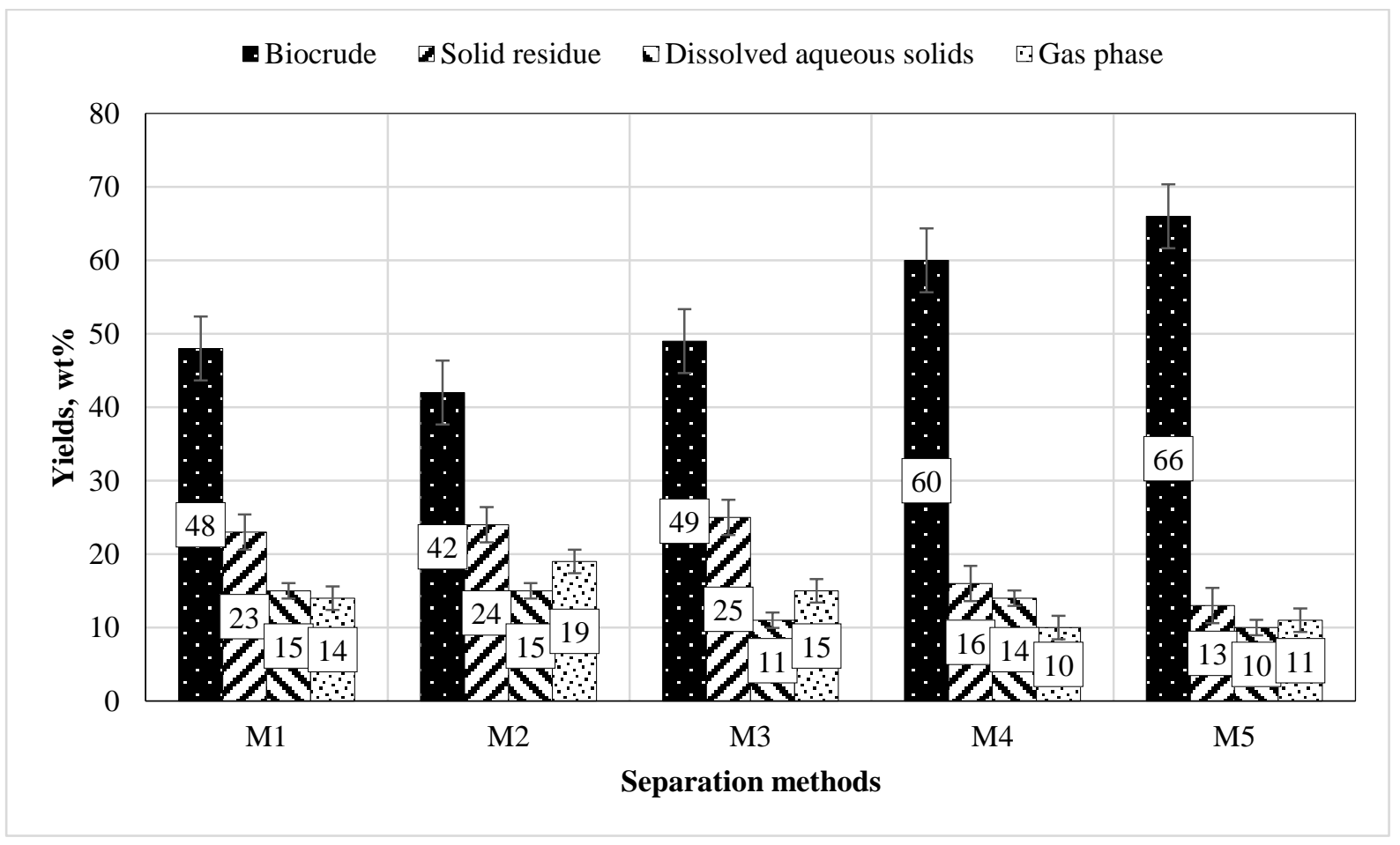

Figure 2: HTL product yields obtained from different separation methods.

$\mathrm{M}_{1}$ : Biocrude phase evaporated at $40^{\circ} \mathrm{C}$, then weighed, no further extraction of biocrude from solid residue and aqueous phase prior to quantification. $\mathrm{M}_{2}$ : Biocrude phase evaporated at $100^{\circ} \mathrm{C}$, then weighed, no further extraction of biocrude from solid residue and aqueous phase prior to quantification. $\mathrm{M}_{3}$ : Biocrude phase evaporated at $100^{\circ} \mathrm{C}$, then weighed, extraction of biocrude from aqueous phase prior to quantification, no extraction of biocrude from residue. $\mathrm{M}_{4}$ : Biocrude phase evaporated at $100^{\circ} \mathrm{C}$, then weighed, extraction of biocrude from residue, prior to quantification, no extraction of biocrude from aqueous phase. $\mathrm{M}_{5}$ : Biocrude phase evaporated at $100^{\circ} \mathrm{C}$, then weighed, extraction of biocrude from both aqueous phase and residue prior to quantification. 


\subsection{Effect of Separation Protocols on Elemental Composition in Biocrude}

Elemental composition of product fractions, particularly biocrude is one of the important factors usually used to determine the quality of HTL products. The elemental distributions in biocrude derived at different separation protocols is illustrated in Fig. 3. As shown in Fig. 3, the elemental content shows little variations. Firstly, the carbon content of biocrude increased from $74 \mathrm{w} / \mathrm{w} \%\left(\mathrm{M}_{1}\right)$ to $76 \mathrm{w} / \mathrm{w} \%\left(\mathrm{M}_{2}\right)$, while the hydrogen content increased from $9.4 \mathrm{w} / \mathrm{w} \%\left(\mathrm{M}_{1}\right)$ to $11 \mathrm{w} / \mathrm{w} \% \quad\left(\mathrm{M}_{2}\right)$. Importantly, the oxygen content reduced from $12.1 \mathrm{w} / \mathrm{w} \%\left(\mathrm{M}_{1}\right)$ to $8.9 \mathrm{w} / \mathrm{w} \%\left(\mathrm{M}_{2}\right)$ with no substantial difference in sulfur content. This finding suggests vacuum evaporation of biocrude phase at $100^{\circ} \mathrm{C}$ improves contents of carbon, and hydrogen, with substantial decrease in oxygen content when compared to that at $40^{\circ} \mathrm{C}$. The enhanced carbon, hydrogen, and decreased in oxygen contents is important, as it improves the energy density of biocrude.
Secondly, similar carbon content were obtained in biocrude from $\mathrm{M}_{3}$, and $\mathrm{M}_{5}$ except for $\mathrm{M}_{4}$. However, the nitrogen content increased from $3.6 \mathrm{w} / \mathrm{w} \%\left(\mathrm{M}_{1}\right)$ to $5 \mathrm{w} / \mathrm{w} \%\left(\mathrm{M}_{3}\right)$ and 5.2w/w\% $\left(\mathrm{M}_{5}\right)$. Although multi-step extraction led to an increase in biocrude yields (shown in Fig. 2), it increases recovery of undesired nitrogeneous compounds. Even biocrudes obtained without multi-step extraction also have high nitrogen content $(3.2 \mathrm{w} / \mathrm{w} \%$ to $3.6 \mathrm{w} / \mathrm{w} \%)$ when compared to $0.1 \mathrm{w} / \mathrm{w} \%$ to $1.2 \mathrm{w} / \mathrm{w} \%$ for petroleum [26]. This finding is in agreement with $\mathrm{Xu}$ and Savage [14] that use of solvent to extract biocrude from HTL product mixture results in an increase of heteroatoms in the biocrude. The nitrogenouos compounds are produced via decomposition of proteins in alga during liquefaction. High nitrogen content in biocrude leads to $\mathrm{NO}_{\mathrm{x}}$ emission during combustion [2]. Hence, upgrading biocrude via hydroprocessing is necessary in order to remove heteroatoms, likewise for biocrudes derived from multistep extraction.

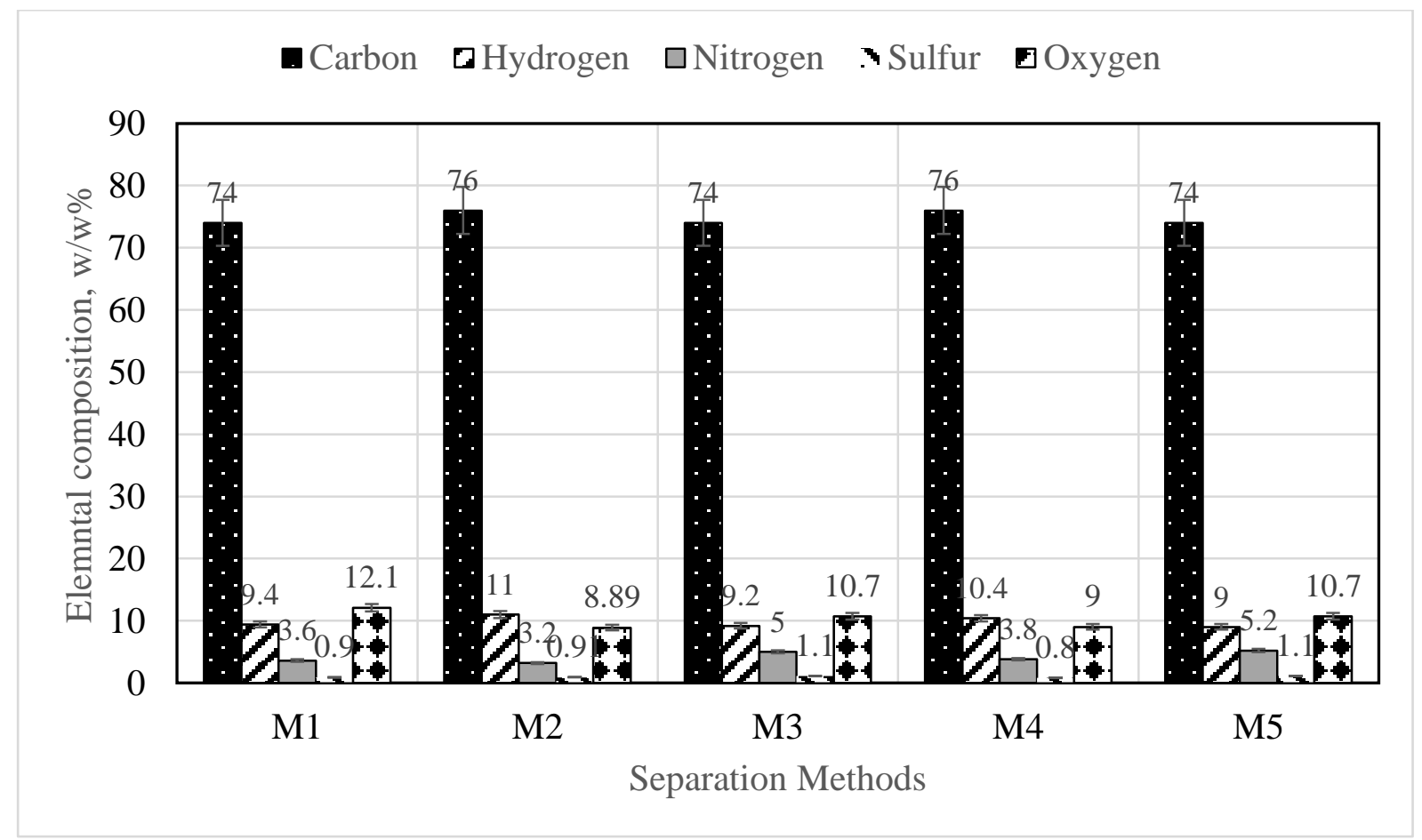

Figure. 3: Elemental distribution in biocrudes obtained from different separation methods.

$\mathrm{M}_{1}$ : Biocrude phase evaporated at $40^{\circ} \mathrm{C}$, then weighed, no further extraction of biocrude from solid residue and aqueous phase prior to quantification. $\mathrm{M}_{2}$ : Biocrude phase evaporated at $100^{\circ} \mathrm{C}$, then weighed, no further extraction of biocrude from solid residue and aqueous phase prior to quantification.

$\mathrm{M}_{3}$ : Biocrude phase evaporated at $100^{\circ} \mathrm{C}$, then weighed, extraction of biocrude from aqueous phase prior to quantification, no extraction of biocrude from residue.

M4: Biocrude phase evaporated at $100^{\circ} \mathrm{C}$, then weighed, extraction of biocrude from residue, prior to quantification, no extraction of biocrude from aqueous phase. $\mathrm{M}_{5}$ : Biocrude phase evaporated at $100^{\circ} \mathrm{C}$, then weighed, extraction of biocrude from both aqueous phase and residue prior to quantification. 
Furthermore, the elemental content of biocrude obtained after solvent extraction of aqueous phase and residue is presented in Fig. 4. As illustrated in Fig. 4, biocrude from aqueous phase has lower carbon content but higher heteroatoms particularly nitrogen, and oxygen contents compared to biocrude derived from residue following solvent extraction. It can be inferred that extraction of biocrude from aqueous phase leads to increase biocrude yield but with nitrogenous and oxygenated-rich molecules. Hence, reduction in energy density and decrease in biocrude quality.

The previous sections have discussed the effects of different separation protocols on the liquid phase; biocrude and aqueous phase. It should be proper to know the influence of the separation methods on solid residue and dissolved aqueous solids (DAS). Here a sample of the solid residue and aquoues phase were analysed for elemental composition and compared with the control sample, where necessary.

The elemental composition of the dissolved aqueous solids from $M_{1}$ and $M_{3}$ are shown in Fig. 5 . Recall that the aquoues phase of $\mathrm{M}_{1}$ did not pass through another solvent extraction step unlike that from $\mathrm{M}_{3}$. Based on the data presented in Fig. 6, it could be concluded that further extraction of biocrude from aqueous phase (for additional biocrude yields) had substantial effects on the dissolved aqueous solids. Generally, the carbon, hydrogen, nitrogen and sulfur contents of DAS from $\mathrm{M}_{3}$ were lower when compared to that from $M_{1}$. The $M_{1}$ DAS carbon contents were $7 \mathrm{w} / \mathrm{w} \%, 3 \mathrm{w} / \mathrm{w} \%$ hydrogen content, $2.8 \mathrm{w} / \mathrm{w} \%$ for nitrogen and $2.2 \mathrm{w} / \mathrm{w} \%$ sulfur contents compared to $\mathrm{M}_{3}$ DAS contents of $3.6 \mathrm{w} / \mathrm{w} \%$, $1.2 \mathrm{w} / \mathrm{w}, 1.5 \mathrm{w} / \mathrm{w} \%$, and $1.5 \mathrm{w} / \mathrm{w} \%$ for carbon, hydrogen, nitrogen and sulfur, respectively. This finding shows that aqueous phase even after solvent extraction of biocrude still contains numerous organic compounds. Therefore solvent extraction of aqueous phase leads to further extraction of hydrocarbons and hetereo-atoms, hence the reduction in the elemental contents. This was evident as colour of $\mathrm{M}_{3}$ aqueous phase was light brown after extraction compared to amber colour of $\mathrm{M}_{1}$ aqueous phase that was not extracted. In addition, the solvent extracted dried solid residues were light grey in colour unlike the unextracted fractions that were dark coloured with greyish particles. The observed dark color suggest presence of unextracted hydrocarbons.

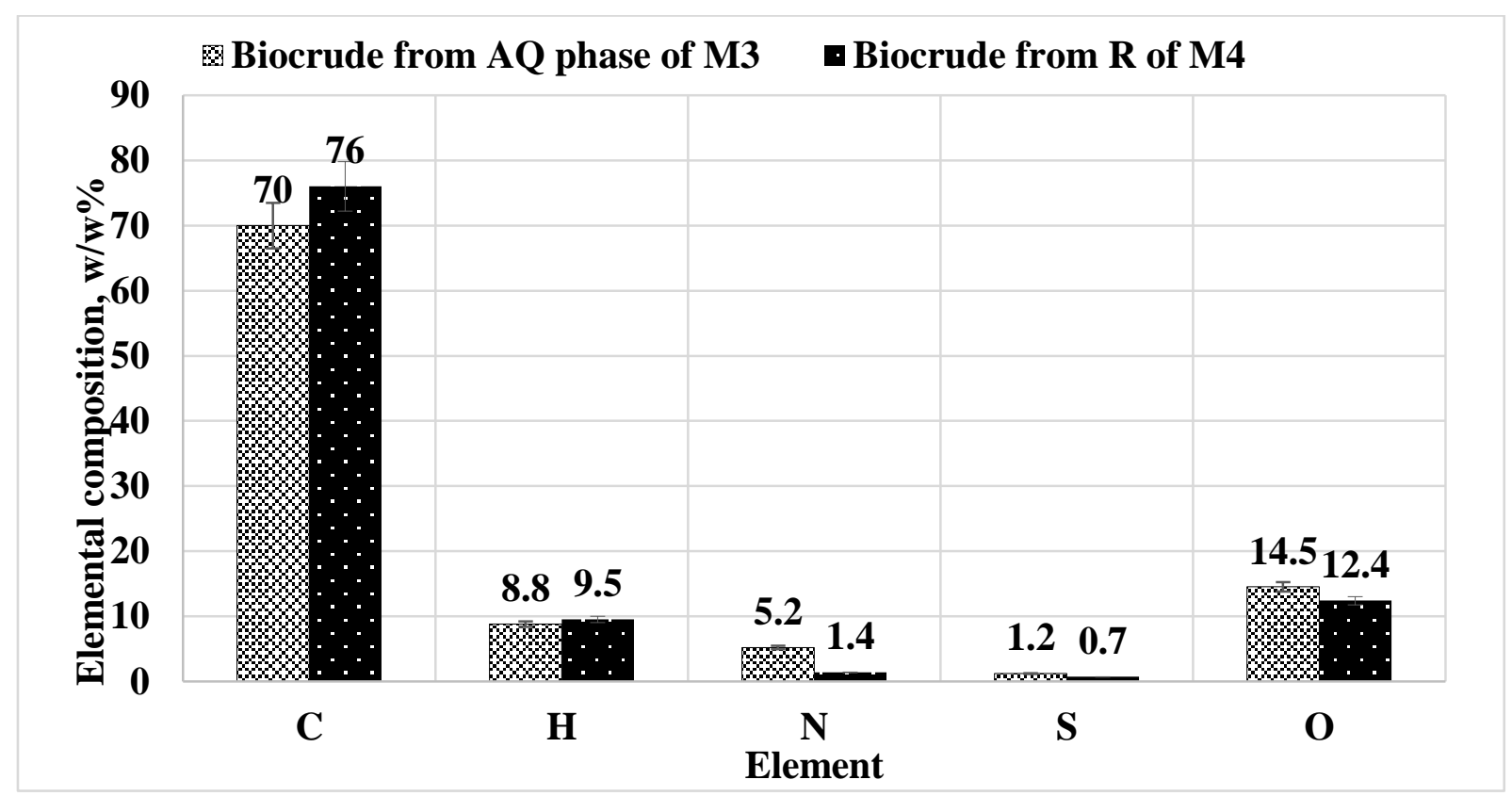

Figure 4: Elemental composition of biocrude extracted from aqueous phase of $M_{3}$ and residue of $M_{4}$

$\mathrm{M}_{1}$ : Biocrude phase evaporated at $40^{\circ} \mathrm{C}$, then weighed, no further extraction of biocrude from solid residue and aqueous phase prior to quantification.

$\mathrm{M}_{4}$ : Biocrude phase evaporated at $100^{\circ} \mathrm{C}$, then weighed, extraction of biocrude from aqueous phase prior to quantification, no extraction of biocrude from residue. 
- Dissolved Aqueous Solids for M1 issolved Aqueous Solids for M3

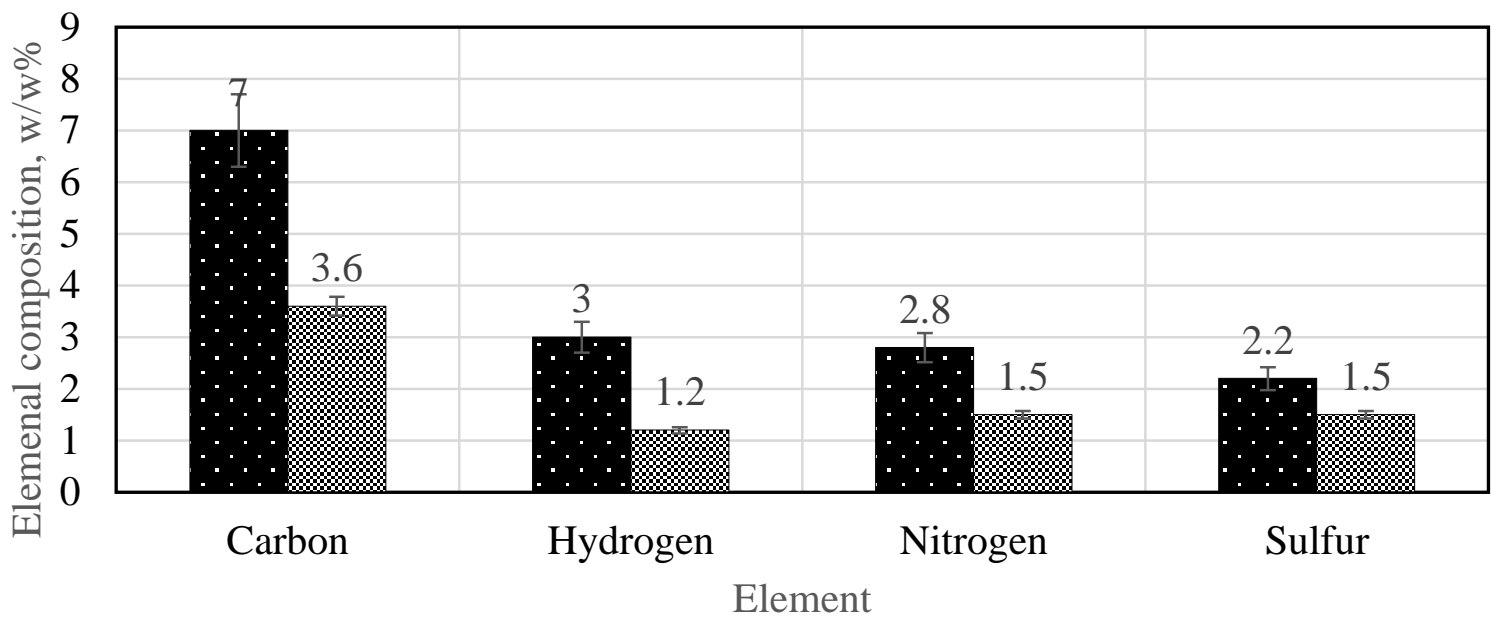

Figure 5: Elemental composition of dissolved aqueous solids obtained from method $M_{1}$ and $M_{3}$.

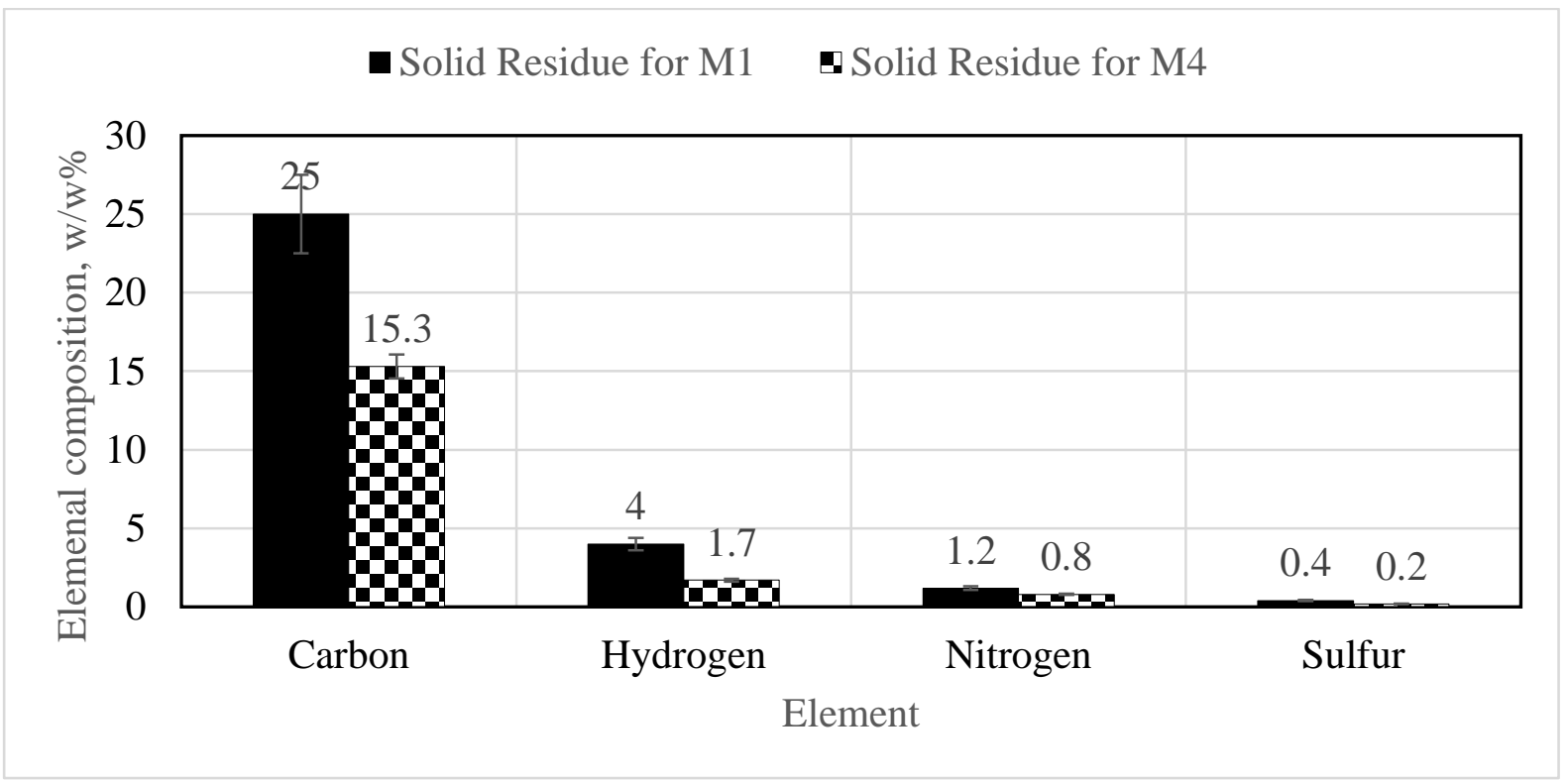

Figure. 6: Elemental composition of solid residue obtained from separation method $M_{1}$ and $M_{4 .}$

$\mathrm{M}_{1}$ : Biocrude phase evaporated at $40^{\circ} \mathrm{C}$, then weighed, no further extraction of biocrude from solid residue and aqueous phase prior to quantification. $\mathrm{M}_{3}$ : biocrude phase evaporated at $100^{\circ} \mathrm{C}$, then weighed, extraction of biocrude from aqueous phase prior to quantification, no extraction of biocrude from residue, M4: Biocrude phase evaporated at $100^{\circ} \mathrm{C}$, then weighed, extraction of biocrude from residue, prior to quantification, no extraction of biocrude from aqueous phase.

Moreover, the elemental composition of the solid residue fractions obtained from $\mathrm{M}_{1}$ (control) and $\mathrm{M}_{4}$ is presented in Fig. 6. As shown in Fig. 6, the contents of carbon $(25 \mathrm{w} / \mathrm{w} \%)$, hydrogen $(4 \mathrm{w} / \mathrm{w} \%)$, nitrogen $(1.2 \mathrm{w} / \mathrm{w} \%)$ and sulfur $(0.4 \mathrm{w} / \mathrm{w} \%)$ from $\mathrm{M}_{1}$ solid residue were higher when compared to $15.3 \mathrm{w} / \mathrm{w} \%$ carbon, $1.7 \mathrm{w} / \mathrm{w} \%$ hydrogen, $0.8 \mathrm{w} / \mathrm{w} \%$ nitrogen and $0.2 \mathrm{w} / \mathrm{w} \%$ sulfur from $\mathrm{M}_{4}$. To the best of my knowledge this is the first report on the properties of solid residue after treating the residue for improved biocrude yield.
Conclusively, multi-step solvent extraction of HTL product mixture has substantial effects on the resultant fractional yields, since there were compositional changes in extracted and un-extracted products.

\subsection{Effect of Separation Protocols on Energy Density}

Biocrude quality is determined in terms of its energy density; higher heating value (HHV), energy recovery (ER) and hydrogen-to-carbon (H/C) atomic ratios. High amounts of these quantities in biocrude are desired to 
improve potentials of HTL-alga-biofuel. Accordingly, the fate of HHV, energy recovery and atomic ratios in resultant biocrude after the multi-step solvent extraction were evaluated. The HHV, ER and (H/C) atomic ratios in biocrudes from various separation protocols are presented in Fig. 7. As shown in Fig. 7, biocrude from $\mathrm{M}_{1}$ has $\mathrm{HHV}$ of $35 \mathrm{MJ} / \mathrm{kg}$ lower than $39 \mathrm{MJ} / \mathrm{kg}$ for $\mathrm{M}_{2}$. This variation shows that vacuum evaporation of biocrude phase at $100^{\circ} \mathrm{C}$ could have favoured deoxygenation reaction, leading to an increase in HHV. Also this finding corroborates with lower oxygen content found for biocrude derived in $\mathrm{M}_{2}$ (Fig. 3).

Furthermore, biocrudes produced from $\mathrm{M}_{3}, \mathrm{M}_{4}$ and $\mathrm{M}_{5}$ has HHVs of $36 \mathrm{MJ} / \mathrm{kg}, 38 \mathrm{MJ} / \mathrm{kg}$ and $34 \mathrm{MJ} / \mathrm{kg}$ respectively. The $38 \mathrm{MJ} / \mathrm{kg}$ derived for $\mathrm{M}_{4}$ biocrude suggests heavy biocrude could have been extracted from the residue fraction unlike for $\mathrm{M}_{3}$ biocrude that was obtained from the aqueous phase. The numerical low $34 \mathrm{MJ} / \mathrm{kg}$ for $\mathrm{M}_{5}$ biocrude suggests presence of certain amounts of $\mathrm{N}$ - and $\mathrm{O}$ - containing compounds (shown in Fig. 3), hence the reduction in its energy value. This study has shown that the higher the $\mathrm{C}$ and $\mathrm{H}$ and lower $\mathrm{N}$ and $\mathrm{O}$ contents in biocrude, the higher the energy value and of better quality.

Moreover, the energy recovery corroborates with biocrude yields. In this study, ER were $71 \%$ for $M_{1}$, $67 \%$ for $M_{2}, 75 \%$ for $M_{3}, 89 \%$ for $M_{4}$ and $86 \%$ for $M_{5}$ and were within the range of reported scientific literature [3, 5, 27]. Skakya et al., [5] reported ER of $47 \%$ for Chlorella sp., $78 \%$ for Scenedesmus sp. and $83 \%$ for Nannochloropsis sp. when operating at $220^{\circ} \mathrm{C}$ to $320^{\circ} \mathrm{C}$ at $30 \mathrm{~min}$. Wang et al., [3] reported ER of $43 \%$ to $61 \%$ from HTL of Nannochloropsis sp. at reaction temperature of $300^{\circ} \mathrm{C}$ and $30 \mathrm{~min}$ time with different catalysts. Eboibi et al., [27] reported up to 87\% ER from liquefaction of Tetrsaelmis sp. at $310^{\circ} \mathrm{C}$ to $370^{\circ} \mathrm{C}$ at $5 \mathrm{~min}$ to $60 \mathrm{~min}$ reaction time. These variations in energy recovery could be due to differences in operating conditions, reactor types and alga species. The $\mathrm{H} / \mathrm{C}$ atomic ratios varies between 1.5 and 1.7, which is within range of previous reports [16, 28], however lower than $\sim 2$ for petroleum. Nevertheless, the $\mathrm{H} / \mathrm{C}$ could be improved following upgrading.

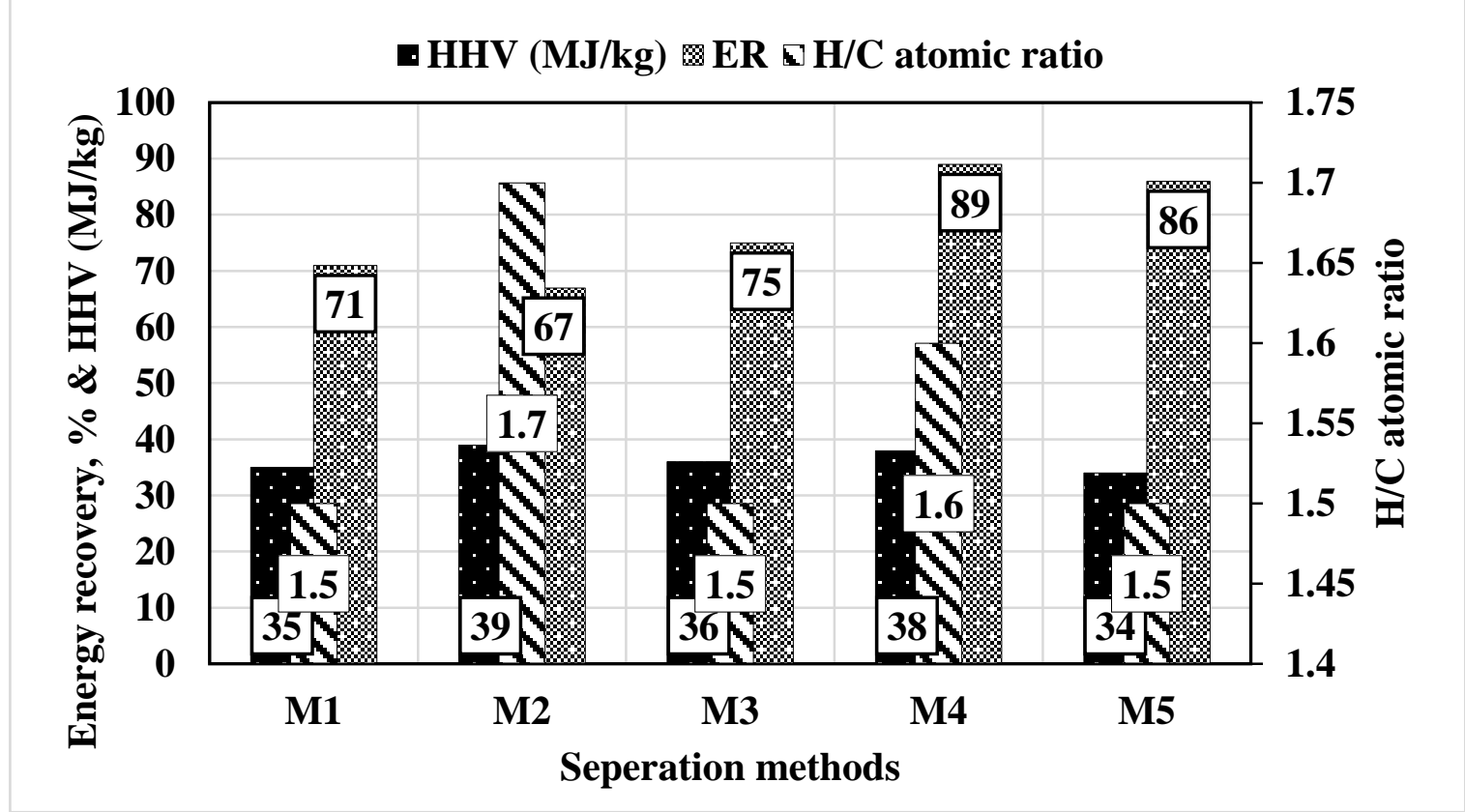

Figure. 7: Heating properties of biocrude obtained at different separation methods

$\mathrm{M}_{1}$ : Biocrude phase evaporated at $40^{\circ} \mathrm{C}$, then weighed, no further extraction of biocrude from solid residue and aqueous phase prior to quantification.

$\mathrm{M}_{2}$ : Biocrude phase evaporated at $100^{\circ} \mathrm{C}$, then weighed, no further extraction of biocrude from solid residue and aqueous phase prior to quantification.

$\mathrm{M}_{3}$ : Biocrude phase evaporated at $100^{\circ} \mathrm{C}$, then weighed, extraction of biocrude from aqueous phase prior to quantification, no extraction of biocrude from residue.

$\mathrm{M}_{4}$ : Biocrude phase evaporated at $100^{\circ} \mathrm{C}$, then weighed, extraction of biocrude from residue, prior to quantification, no extraction of biocrude from aqueous phase.

M5: Biocrude phase evaporated at $100^{\circ} \mathrm{C}$, then weighed, extraction of biocrude from both aqueous phase and residue prior to quantification. 
In summary, this present study has shown that vacuum evaporation of biocrude phase at $40^{\circ} \mathrm{C}$ tends to leaves some water molecules in biocrude, which is calculated alongside yield in biocrude.

Whereas vacuum evaporation at $100^{\circ} \mathrm{C}$ favours reduction in oxygenated compounds, improving biocrude quality. Multi-step solvent extraction of residue aqueous phase led to increased biocrude yields but favours fractionation of $\mathrm{O}$-and $\mathrm{N}$-compounds in resultant biocrude. HTL is a wet process, so it is a challenge to avoid breakdown of macromolecules to undesired nitrogenous and oxygenated compounds in biocrude. Although organic solvent helps to extract hydrocarbons from the product mixture, it enhances recovery of nitrogen- and oxygen-containing compounds in the biocrude [14, 29].

The recovery of biocrude with lower $\mathrm{N}$ - and $\mathrm{O}$ - contents is possible without solvent extraction [14, 29] and economical, however low yields were obtained. Also few quantity of light hydrocarbons are obtained and amounts recovered are strongly dependent on alga component. Nevertheless, HTL-alga-biocrudes obtained with or without solvent fall short of standard fuel specifications, thus upgrading is required. Therefore solvent extraction may still be applied until improved technology is available.

Table 1: Chemical composition of biocrudes obtained from different separation methods

\begin{tabular}{|c|c|c|c|c|c|c|}
\hline \multirow[t]{2}{*}{$\mathrm{S} / \mathrm{N}$} & \multirow[t]{2}{*}{ Compounds } & \multicolumn{5}{|c|}{ Relative abundance (area \%) } \\
\hline & & $\mathrm{M}_{1}$ & $\mathrm{M}_{2}$ & $\mathrm{M}_{3}$ & $\mathrm{M}_{4}$ & $\mathrm{M}_{5}$ \\
\hline & Oxygenated compounds & & & & & \\
\hline 1 & Aldehydes & 1.2 & 0.4 & bdl & bdl & 0.4 \\
\hline 2 & Carboxylic acids & 4.2 & 5.02 & 5.8 & 5.2 & 10.4 \\
\hline 3 & Esters & 1.6 & 1.2 & 0.1 & bdl & 0.5 \\
\hline \multirow[t]{2}{*}{4} & Ketones & 4.4 & 4.1 & 0.4 & 2.2 & 5.7 \\
\hline & Total & 11.4 & 10.72 & 6.2 & 7.4 & 14 \\
\hline & Nitrogenated compounds & & & & & \\
\hline 5 & Amides & 4.4 & 4.1 & 5.3 & 5.0 & 5.6 \\
\hline 6 & Amines & 3.8 & 3.2 & 3.5 & 3.4 & 3.6 \\
\hline 7 & Nitriles & 0.2 & 0.1 & 0.2 & bdl & 0.8 \\
\hline \multirow[t]{2}{*}{8} & Piperidine & 0.2 & bdl & 0.2 & 0.1 & 0.9 \\
\hline & Total & 8.6 & 7.4 & 9.2 & 8.5 & 20.5 \\
\hline 9 & Aliphatic & & & & & \\
\hline 10 & n-Alcanes & 9.1 & 8.4 & 8.3 & 7.4 & 12.1 \\
\hline 11 & Alkane methyl derivatives & 3.4 & 3.1 & 5.2 & 2.2 & 6.6 \\
\hline \multirow[t]{3}{*}{12} & Alkene methyl derivatives & 2.0 & 2.0 & 2.0 & 1.8 & 2.7 \\
\hline & Total & 16.3 & 13.5 & 15.5 & 11.4 & 21.4 \\
\hline & Monoaromatics & & & & & \\
\hline \multirow{3}{*}{$\begin{array}{l}13 \\
14 \\
15\end{array}$} & Benzene & 1.5 & 1.5 & 1.0 & bdl & 1.3 \\
\hline & Cyclohexane & 1.0 & 0.9 & 1.1 & bdl & 2.1 \\
\hline & $\begin{array}{l}\text { Phenol methyl/ethyl } \\
\text { derivatives }\end{array}$ & 1.2 & 1.1 & 2.8 & 2.2 & 5.35 \\
\hline 16 & Styrene & 11.2 & 11.4 & 12.8 & 11.3 & 13.2 \\
\hline \multirow[t]{2}{*}{17} & Toluene & 4.4 & 4.3 & 5.2 & 4.6 & 7.1 \\
\hline & Total & 19.3 & 19.2 & 22.9 & 18.1 & 29.1 \\
\hline
\end{tabular}

bdl: below detection limit.

$\mathrm{M}_{1}$ : Biocrude phase evaporated at $40^{\circ} \mathrm{C}$, then weighed, no further extraction of biocrude from solid residue and aqueous phase prior to quantification.

$\mathrm{M}_{2}$ : Biocrude phase evaporated at $100^{\circ} \mathrm{C}$, then weighed, no further extraction of biocrude from solid residue and aqueous phase prior to quantification.

$\mathrm{M}_{3}$ : Biocrude phase evaporated at $100^{\circ} \mathrm{C}$, then weighed, extraction of biocrude from aqueous phase prior to quantification, no extraction of biocrude from residue.

$\mathrm{M}_{4}$ : Biocrude phase evaporated at $100^{\circ} \mathrm{C}$, then weighed, extraction of biocrude from residue, prior to quantification, no extraction of biocrude from aqueous phase.

M5: Biocrude phase evaporated at $100^{\circ} \mathrm{C}$, then weighed, extraction of biocrude from both aqueous phase and residue prior to quantification. 


\subsection{Chemical Composition of Biocrudes}

Data obtained from the GC-MS analysis of biocrudes obtained from $\mathrm{M}_{1}$ to $\mathrm{M}_{5}$ are presented in Table 1. As shown in Table 1, biocrude is a complex mixture containing numerous oxygenated compounds (aldehydes, carboxylic acids, esters and ketones), nitrogenated compounds such as amides and amines; aliphatic compounds (e.g. alkanes and alkenes and their derivatives); and monoaromatics compounds (such as benzene, cyclohexane, furans, phenols, styrene and toluene). Although there were no much difference between relative abundance of biocrude from $\mathrm{M}_{2}$ and $\mathrm{M}_{1}$, the numerical difference could be mostly due to variation in vacuum temperature. Generally, biocrude derived from $\mathrm{M}_{5}$ had higher relative abundance in 0 and N-compounds, aliphatic and monoaromatic compounds when compared to $\mathrm{M}_{1}$ to $\mathrm{M}_{4}$. The high $\mathrm{O}$ and $\mathrm{N}$-compounds were consistent with results obtained for elemental analysis which showed that $M_{5}$, $\mathrm{M}_{3}$ and $\mathrm{M}_{1}$ biocrude component are richer in $\mathrm{O}$-and $\mathrm{N}$ contents. This reaffirms multi-step extraction enhances recovery of undesired compounds such as oxygenated and nitrogenated compounds in biocrude, though it led to an increase in biocrude yield.

\section{CONCLUSION}

The results of this study shows that vacuum evaporation of biocrude phase at $100^{\circ} \mathrm{C}$ led to better 'quality' biocrude, but with low biocrude yields when compared with $40^{\circ} \mathrm{C}$ evaporation. Multi-step solvent extraction of product mixture led to $\sim 65 \mathrm{wt} \%$ biocrude yield compared to $\sim 48 \mathrm{wt} \%$ for single step. Multistep solvent extraction led to increase biocrude yield, and lower yields in solid residue and aqueous phases. However at the expense of nitrogenous and oxygenated containing compounds in resultant biocrude. The different separation methods had little impact on the higher heating value and $\mathrm{H} / \mathrm{C}$ atomic ratios of biocrude which varies between $34 \mathrm{MJ} / \mathrm{kg}$ and $38 \mathrm{MJ} / \mathrm{kg}$ and 1.5 and 1.7 , respectively.

\section{ACKNOWLEDGEMENTS}

This research was supported under the Australian Research Council's Linkage Projects funding scheme (ARC LP 100200616) with industry partner SQC Pty Ltd and the Australian Renewable Energy Agency (ARENA) advanced biofuels investment readiness program funding number Q00150. The author acknowledges support provided by Postgraduate Research Award provided by Education Trust Fund of the Federal Republic of Nigeria. Eboibi appreciate the support and technical assistance provided by Aban Infrastructure Pvt Ltd and the R\&D division of Chennai Petroleum Corporation Limited, Chennai, India

\section{REFERENCES}

[1] Peterson, A. A., Vogel, F., Lachance, R. P., Froling, M, Antal, Jr. M. J., and Tester, J. W "Thermochemical biofuel production in hydrothermal media: A review of sub-and supercritical water technologies". Energy Environ. Sci, 1, pp. 32-65, 2008.

[2] Toor, S. S, Rosendahl, L, Rudolf, A "Hydrothermal liquefaction of biomass: A review of subcritical water technologies". Energy, 36, pp. 2318-2342, 2011.

[3] Wang, W, Xua, Y, Wanga, X, Zhang, B, Tiana, W, and Zhang, J "Hydrothermal liquefaction of microalgae over transition metal supported $\mathrm{TiO} 2$ catalyst" Bioresource Technol., 250, pp. 474-480, 2018.

[4] Wagner, J. L, Le, C. D, Ting, V. P, and Chuck, C. J "Design and operation of an inexpensive, laboratory-scale, continuous hydrothermal liquefaction reactor for the conversion of microalgae produced during wastewater treatment" Fuel Processing Technol. 165, pp. 102$111,2017$.

[5] Shakya, R, Adhikaria, S, Mahadevan, R, Shanmugam, SR, Nam, H, Hassanb, E. B and Dempster, T. A "Influence of biochemical composition during hydrothermal liquefaction of algae on product yields and fuel properties" Bioresource Technol, 243, pp. 1112-1120, 2017.

[6] Vlaskin, M. S, Chernov, N. I, Kiselev, S. V, Popel', O. S; and Zhuk, A. Z "Hydrothermal Liquefaction of Microalgae to Produce Biofuels: State of the Art and Future Prospects" Thermal Engineering, 64, pp. 627-636, 2017.

[7] Jiang, J and Savage, P. E "Metals and other elements in biocrude from fast and isothermal hydrothermal liquefaction of microalgae" Energy Fuels, DOI:10.1021/acs.energyfuels.7b03144

[8] $\mathrm{Xu}, \mathrm{D}$ and Savage, P. E "Supercritical water upgrading of water-insoluble and water-soluble biocrudes from hydrothermal liquefaction of Nannochloropsis microalga". The Journal Supercitical Fluids, 133, pp. 683-689, 2018.

[9] Valdez, P. J and Savage, P. E. "A reaction network for the hydrothermal liquefaction of Nannochloropsis sp." Algal Research, 2, pp. 416425, 2013.

[10] Xu, D and Savage, P. E "Effect of reaction time and algae loading on water-soluble and insoluble biocrude fractions from hydrothermal 
liquefaction of alga" Algal Research, 21, pp. 60-67, 2015.

[11] Biller, P, Ross, A.B, Skill, S.C, Lea-Langton, A, Balasundaram, B, Hall, C, Riley, R, and Llewellyn, C.A "Nutrient recycling of aqueous phase for microalgae cultivation from the hydrothermal liquefaction process" Algal Research, 1, pp. 70-76, 2012.

[12] Edmundson, S, Huesemann, M, Kruk, R, Lemmon, T, Billing, J, Schmidt, A, and Anderson, D "Phosphorus and nitrogen recycle following algal bio-crude production via continuous hydrothermal liquefaction" Algal Research, 26, pp. 415-421, 2017.

[13] Nelson, M, Zhu, L, Thiel, A, Wua, Y, Guan, M, Minty, J, Wang, H.Y, Lin, N.X "Microbial utilization of aqueous co-products from hydrothermal liquefaction of microalgae Nannochloropsis oculata" Bioresource Technol., 136, pp. 522-528, 2013.

[14] Xu, D and Savage, P. E "Characterization of biocrudes recovered with and without solvent after hydrothermal liquefaction of algae" Algal research, 6, pp. 1-7, 2014.

[15] Jena, U, Das, K. C, and Kastner, J.R "Effect of operating conditions of thermochemical liquefaction on biocrude" Bioresource Technol, 102, pp. 6221-6229, 2011.

[16] Eboibi, B. E, Lewis, D. M, Ashman, P. J, and Chinnasamy, S "Inluence of process conditions on pretreatment of microalgae for protein extration and production of biocrude during hydrothermal liquefaction of pretreated Tetraselmis sp." RSC $A d V .$, 5, pp. 20193-20207, 2015.

[17] Fon Sing, S, Isdepsky, M, Borowitzka, A, and Lewis, D.M "Pilot scale continuoius recycling of growth medium for the mass culture of a halotolerant Tetraselmis $\mathrm{sp}$. in raceway ponds under increasing salinity: a novel protocol for commercial microalgal biomass production" Bioresource Technol., 161, pp. 47-54, 2014.

[18] $\mathrm{Hu}, \mathrm{H}-\mathrm{S}, \mathrm{Wu}, \mathrm{Y}-\mathrm{L}$, and Yang, M-D "Fractionation of bio-oil produced from hydrothermal liquefaction of microalgae by liquid-liquid extraction" Biomass Bioenergy, 108, pp. 487-500, 2018.

[19] Sheng, L, Wang, X, and Yang, X “Prediction model of biocrude yield and nitrogen heterocyclic compounds analysis by hydrothermal liquefaction of microalgae with model compounds" Bioresource Technol, 247, pp. 14-20, 2018.
[20] Wang, W, Zhang, S, Yu, Q, Lin, Y, Yang, N, Han, W and Zhang, J. "Hydrothermal liquefaction of high protein microalgae via clay material catalysts" RSC AdV., 7, pp. $50794-50801,2017$.

[21] Bai, X, Duan, P, Xu, Y, Zhang, A and Savage, P. E "Hydrothermal catalytic processing of pretreated alga oil: a catalyst screening study" Fuel, 120, pp. 141-149, 2014

[22] Cheng, F, Cui, Z, Mallick, K, Nirmalakhandan, N and Brewer, C.E "Hydrothermal liquefaction of highand low-lipid algae: Mass and energy balances" Bioresource Technol. 258, pp. 158-167, 2018.

[23] Yang, W, Li, X, Zhang, D and Feng, L “Catalytic upgrading of bio-oil in hydrothermal liquefaction of algae major model components over liquid acids" Energy Conversion and Mgt. 154, pp. 336343, 2017.

[24] Alba, L. G, Torri, C, Samorì, C, van der Spek, J, Fabbri, D, Kersten, S.R.A and Brilman, D. W. F "Hydrothermal Treatment (HTT) of Microalgae: Evaluation of the process as conversion method in an algae biorefinery concept" Energy Fuel, 26, pp. 642-657, 2012.

[25] Zhu, Z, Si, B, Lu, J, Watson, J, Zhang, Y, and Liu, Z "Elemental migration and characterization of products during hydrothermal liquefaction of cornstalk" Bioresource Technol. 243, pp. 9-16, 2017.

[26] Speight, G "The Chemistry and Technology of Petroleum, third ed. Marcel Dekker Inc. New York, 1999.

[27] Eboibi, B. E, Lewis, D. M, Ashman, P. J, and Chinnasamy, S "Effect of operating conditions on yield and quality of biocrude during hydrothermal liquefaction of halophytic Tetraselmis sp. alga" Bioresource Technol., 174, pp. 20-29, 2014.

[28] Hadhoum, L, Balistrou, M, Burnens, G, and Loubar, $\mathrm{K}$ "Mohand Tazeroutb Hydrothermal liquefaction of oil mill wastewater for bio-oil production in subcritical conditions" Bioresource Technol., 216, pp. 9-17, 2016.

[29] Elliott, D. C, Hart, T. R, Schmidt, A. J, Neuenschwander, G.G, Rotness, L. J, Olarte, M. V, Zacher, A. H; Albrecht, K. O, Hallen, R. T and Hollada, J. E "Process development for hydrothermal liquefaction of algae feedstocks in a continuous-flow reactor" Algal Research 2, pp. 445-454, 2013. 